\title{
The Role of Blood Biomarkers for Magnetic Resonance Imaging Diagnosis of Traumatic Brain Injury
}

\author{
John K. Yue ${ }^{1,2, *,+}$, Pavan S. Upadhyayula ${ }^{3,4,+}$, , Lauro N. Avalos ${ }^{1}$, Hansen Deng ${ }^{5}$ and \\ Kevin K. W. Wang ${ }^{6}$ \\ 1 Department of Neurological Surgery, University of California San Francisco, San Francisco, CA 94143, USA; \\ Lauro.Avalos@ucsf.edu \\ 2 Brain and Spinal Injury Center, Zuckerberg San Francisco General Hospital, San Francisco, CA 94110, USA \\ 3 Department of Neurological Surgery, Columbia University Medical Center, New York, NY 10027, USA; \\ pavan8632@gmail.com \\ 4 Department of Neurological Surgery, University of California Diego, San Diego, CA 92093, USA \\ 5 Department of Neurological Surgery, University of Pittsburgh Medical Center, Pittsburgh, PA 15213, USA; \\ dengh3@upmc.edu \\ 6 Brain Rehabilitation Research Center (BRRC), Malcom Randall Veterans Affairs Medical Center, Gainesville, \\ FL 32608, USA; kawangwang17@gmail.com \\ * Correspondence: john.yue@ucsf.edu; Tel./Fax: +1-415-206-8300 \\ $\dagger$ Authors contributed equally to this work.
}

Received: 20 December 2019; Accepted: 19 February 2020; Published: 22 February 2020

Abstract: Background and Objectives: The annual global incidence of traumatic brain injury (TBI) is over 10 million. An estimated $29 \%$ of TBI patients with negative computed tomography (CT-) have positive magnetic resonance imaging (MRI+) findings. Judicious use of serum biomarkers with MRI may aid in diagnosis of CT-occult TBI. The current manuscript aimed to evaluate the diagnostic, therapeutic and risk-stratification utility of known biomarkers and intracranial MRI pathology. Materials and Methods: The PubMed database was queried with keywords (plasma OR serum) AND (biomarker OR marker OR protein) AND (brain injury/trauma OR head injury/trauma OR concussion) AND (magnetic resonance imaging/MRI) (title/abstract) in English. Seventeen articles on TBI biomarkers and MRI were included: S100 calcium-binding protein B (S100B; $N=6)$, glial fibrillary acidic protein (GFAP; $N=3)$, GFAP/ubiquitin carboxyl-terminal hydrolase-L1 (UCH-L1; $N=2)$, Tau $(N=2)$, neurofilament-light (NF-L; $N=2$ ), alpha-synuclein $(N=1)$, and alpha-amino-3-hydroxy-5-methyl-4-isoxazolepropionic acid receptor peptide (AMPAR; $N=1$ ). Results: Acute GFAP distinguished CT-/MRI+ from $\mathrm{CT}-\mathrm{MRI}-(\mathrm{AUC}=0.777,0.852$ at 9-16 h). GFAP discriminated CT-/diffuse axonal injury (DAI+) from controls (AUC $=0.903$ ). Tau correlated directly with number of head strikes and inversely with white matter fractional anisotropy (FA), and a cutoff $>1.5 \mathrm{pg} / \mathrm{mL}$ discriminated between DAI+ and DAI- (sensitivity $=74 \% /$ specificity $=69 \%$ ). NF-L had $100 \%$ discrimination of DAI in severe TBI and correlated with FA. Low alpha-synuclein was associated with poorer functional connectivity. AMPAR cutoff $>0.4 \mathrm{ng} / \mathrm{mL}$ had a sensitivity of $91 \%$ and a specificity of $92 \%$ for concussion and was associated with minor MRI findings. Low/undetectable S100B had a high negative predictive value for CT/MRI pathology. UCH-L1 showed no notable correlations with MRI. Conclusions: An acute circulating biomarker capable of discriminating intracranial MRI abnormalities is critical to establishing diagnosis for CT-occult TBI and can triage patients who may benefit from outpatient MRI, surveillance and/or follow up with TBI specialists. GFAP has shown diagnostic potential for MRI findings such as DAI and awaits further validation. Tau shows promise in detecting DAI and disrupted functional connectivity. Candidate biomarkers should be evaluated within the context of analytical performance of the assays used, as well as the post-injury timeframe for blood collection relative to MRI abnormalities. 
Keywords: blood-based biomarkers; diagnosis; magnetic resonance imaging; traumatic brain injury

\section{Introduction}

Traumatic brain injury (TBI) is a leading cause of death and disability, with an annual global incidence of over 10 million cases. Accurate diagnosis, triage and treatment are critical public health necessities [1-3]. Initial evaluation utilizes the Glasgow Coma Scale (GCS) score, which incorporates eye, verbal, and motor response to categorize neurologic dysfunction into severe (GCS 3-8), moderate (GCS 9-12) and mild (GCS 13-15) TBI. It is increasingly evident that even patients with mild TBI (mTBI) are at risk of intracranial hemorrhage and non-grossly hemorrhagic injury such as axonal shear on presentation, as well as persistent functional deficits at or beyond 3 months post-injury [4]. Evidence over the past two decades has shown that GCS alone may not be sufficient to diagnose or prognosticate TBI, especially on the mild end of the spectrum [3].

Current standard of care for TBI relies on computed tomography (CT) due to its specificity for hemorrhage, fractures, and rapid acquisition time [5]. However, magnetic resonance imaging (MRI) has been shown to be increasingly important for certain TBI subpopulations. MRI is more sensitive to nearly all forms of intracranial injury apart from acute hemorrhage and fractures due to its ability for evaluation of axonal shear, small contusions, and hypoxic injury. Beyond its use in the acute TBI, MRI can also evaluate volumetric loss in chronic TBI. Acute TBI may present as CT negative/MRI positive (CT-/MRI+) or CT negative/MRI negative (CT-/MRI-). The use of adjunct diagnostic techniques such as serum biomarkers can further diagnose and/or risk stratify patients with suspected TBI. The ideal serum biomarker should have high specificity for brain tissue, high sensitivity for brain injury, and stable kinetics. Several serum biomarkers have been widely studied in clinical settings as potential biomarkers for TBI severity and risk stratification. These include S100 calcium-binding protein B (S100B), glial fibrillary acidic protein (GFAP), ubiquitin carboxy-terminal hydrolase-L1 (UCH-L1), neurofilament light protein (NF-L), Tau protein, and others. We summarize the relevant data related to these biomarkers and their utility for diagnosis of TBI.

\section{Materials and Methods}

\subsection{Study Selection}

The National Library of Medicine PubMed database was queried using the search terms ((plasma (title/abstract) OR serum (title/abstract)) AND (biomarker (title/abstract) OR marker (title/abstract) OR protein (title/abstract)) AND (brain injury (title/abstract) OR head injury (title/abstract) OR head trauma (title/abstract) OR concussion (title/abstract)) AND (magnetic resonance imaging (title/abstract) OR MRI (title/abstract)) in the English language. Primary literature on humans, excluding case reports, was included in the current review. Study authors reviewed each article and determined its relevance to plasma/serum biomarkers and MRI (magnetic resonance imaging) in TBI, and all articles were unanimously included or excluded.

\subsection{Inclusion and Exclusion Criteria}

Studies were included if they studied an adult population (age $>18$ ), studied a patient population with traumatic brain injury, studied a serum biomarker and had patients who had MRI data. Studies were excluded if they were not in the English language, were animal research or basic science, lacked MRI imaging, or were case reports or reviews.

\subsection{Article Summary}

Of 86 articles from the initial search, 18 were selected for inclusion (Figure 1), which included $\operatorname{S100B}(N=6), \operatorname{GFAP}(N=3), \operatorname{GFAP} / \mathrm{UCH}-\mathrm{L} 1(N=2)$, Tau $(N=2), \mathrm{NF}-\mathrm{L}(N=2)$, and alpha-synuclein 
$(N=1)$, AMPAR $(N=1)$. Sixty-eight articles were excluded for the following reasons: article was in non-English language $(N=2)$, animal or basic science focus $(N=14)$, the primary focus was not $\mathrm{TBI} /$ concussion $(N=38)$, no or mixed MRI data $(N=5)$, non-serum biomarker focus $(N=3)$ case report $(N=2)$, literature review $(N=3)$, and duplicate entry $(N=1)$.

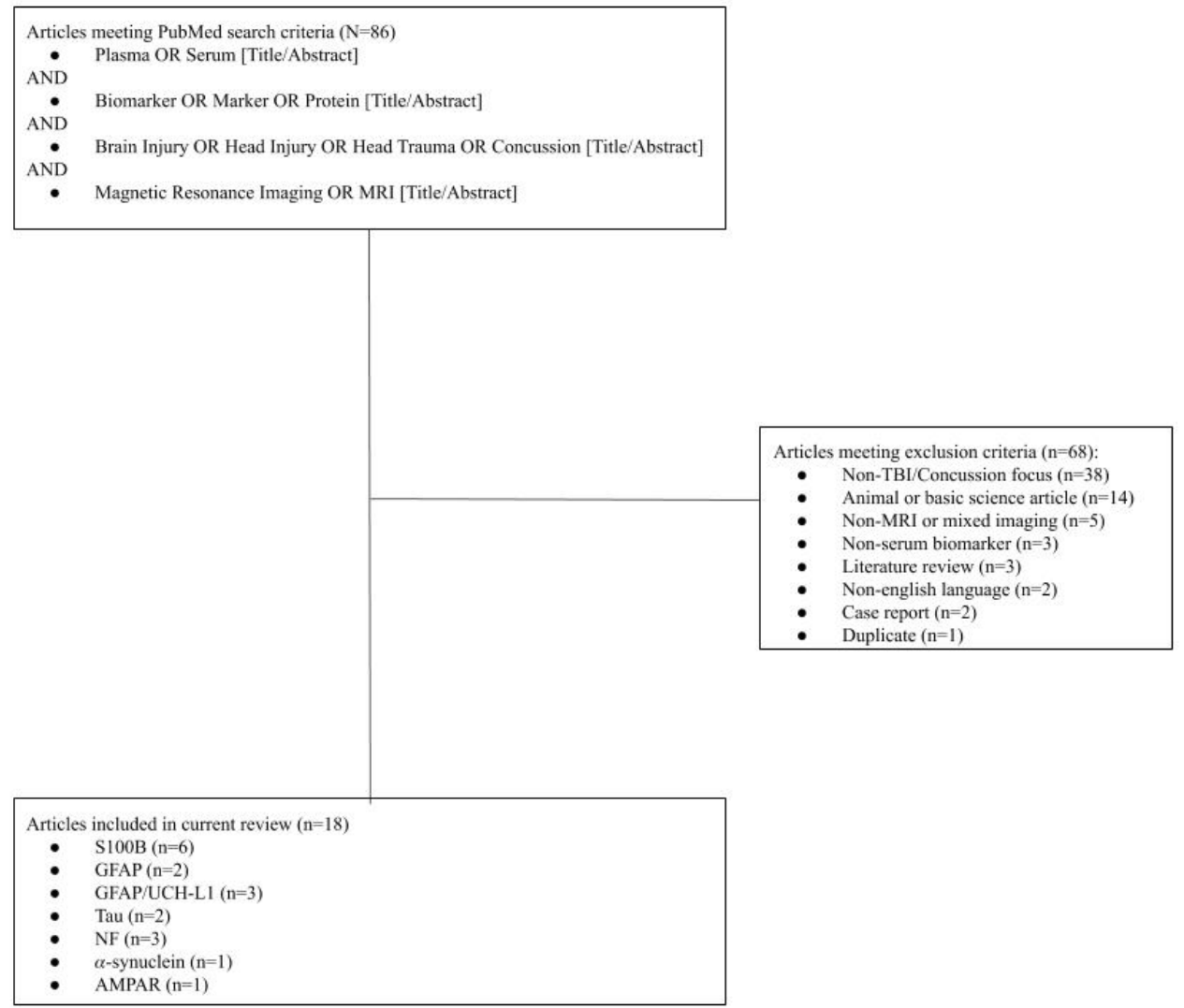

Figure 1. Flow Diagram of Included Articles.

\section{Results}

Table 1 displays studies qualifying for review in the current manuscript.

\subsection{S100 Calcium-Binding Protein B (S100B; 6 Studies)}

S100B is a calcium-binding protein synthesized in astroglial and Schwann cells, primarily found in white matter, and has been one of the longest-studied proteomic biomarkers for TBI [6]. S100B has a half-life of $2 \mathrm{~h}$. The earliest prospective study on S100B and radiographic evidence was performed by Herrmann et al. in 1999. This study, however, did not differentiate between CT and MRI, nor did they find associations between S100B release patterns and radiographic findings [6]. Ingebrigtsen et al., studied 45 CT-negative mTBI patients who received 0.5 T MRIs and had S100B drawn immediately at presentation as well as at a second time point within $12 \mathrm{~h}$ of presentation. Mean S100B declined from time of injury, and within the $28 \%$ with detectable S100B, $60 \%$ had returned to below the detection limit within $7 \mathrm{~h}$ of injury. Four of the five patients (80\%) were MRI+ for contusion and had elevated serum S100B (>0.2 ug/L), which differed significantly with those who were MRI-negative. Patients with elevated S100B also had poorer 3 month attention, memory, and processing speed [7]. Romner et al. drew S100B within $24 \mathrm{~h}$ of injury in mTBI patients-a subset of whom underwent $0.5 \mathrm{~T}$ MRI $(N=45)$ and five had contusions. While not a direct comparison, $80 \%$ of those with MRI+ contusions had S100B $>0.2 \mathrm{ug} / \mathrm{L}$, vs. $30 \%$ for those who were radiographically negative $(N=228)$ [8]. The authors concluded that undetectable S100B predicts normal intracranial findings on $\mathrm{CT}$, although no comment is made for MRI [8]. In 2007, Oh et al. investigated the Elecsys immunoassay in the ED in 32 TBI 
patients who were CT/MRI+ (mean $0.253 \mathrm{ug} / \mathrm{L}$ ) vs. 13 patients who were CT-/MRI- (mean 0.098 ug/L, $p=0.028)$ [9]. The authors found a similar trend in nontraumatic brain injury $(0.179 \mathrm{vs} .0 .057 \mathrm{ug} / \mathrm{L} ; N$ $=34$ vs. $N=22, p=0.037$ ). The overall AUC for detecting CT-/MRI+ vs. CT-/MRI- brain injury was $0.839(95 \%$ CI $0.748-0.929, p<0.001)$, with a sensitivity of $84.8 \%$ and specificity of $74.3 \%$ at a S100B cutoff of $0.105 \mathrm{ug} / \mathrm{L}$. However, the authors do not differentiate between CT and MRI+ brain injury [9]. In 2013, Thelin et al. reported on 250 TBI patients regarding a second S100B peak after $48 \mathrm{~h}$ of injury in $39 \%$ of patients, which correlated with radiographic injury - most frequently ischemia/infarction (70 of 98) followed by edema (15 of 98) [10]. This study, similar to other aforementioned studies, did not differentiate between CT and MRI findings and therefore is of limited utility to the goals of the current review.

Finally, a small study in 2016 by Linsenmaier et al. using the Elecsys S100B assay showed in $41 \mathrm{mTBI}$ patients that while all 29 CT-negative scans were $1.5 \mathrm{~T}$ MRI-negative, of the $12 \mathrm{CT}+$ scans, only five were MRI+; six were false positives, and one was a cavernous angioma (nontraumatic) [11]. Using a S100B cutoff of $0.1 \mathrm{ug} / \mathrm{L}$, the study found PPV 16\% and NPV 100\% for MRI+ intracranial lesions [11].

In 2013, Marchi et al. investigated pre- and post-game $(<24 \mathrm{~h})$ serum S100B levels in 67 non-concussed college football players and obtained three diffusion tensor imaging (DTI) scans to evaluate for white matter changes [12]. The authors found that transient blood-brain barrier (BBB) damage measured by S100B, as well as S100B auto-antibodies, was detected in players with the greatest number of subconcussive head strikes (6 strikes: mean $0.10 \mathrm{ug} / \mathrm{L}, 0$ strikes: mean $0.02 \mathrm{ug} / \mathrm{L}, p=0.030$; played with head hits: mean $0.11 \mathrm{ug} / \mathrm{L}$, played $<5$ min: mean $0.01 \mathrm{ug} / \mathrm{L}$ ) [12]. S100B auto-antibodies also predicted persistent DTI abnormalities and cognitive changes. The authors also show that in the absence of concussions, S100B tends to return quickly to baseline after a game. The authors concluded that cumulative subconcussive head strikes may lead to BBB disruption, and elevated serum S100B, with implications for risk assessment [12]. There is also the implication that circulating autoantibodies against a CNS antigen can become pathogenic to the brain when BBB disruption occurs and/or otherwise allows their access into the brain [13].

\subsection{Glial Fibrillary Acidic Protein (GFAP; 5 Studies)}

GFAP is an intermediate filament abundantly present in astrocytes of the central nervous system. The reactive astrocytic response to brain trauma in the context of BBB disruption forms the basis of interest in this biomarker of TBI [14]. The literature on the relationship between GFAP and MRI in TBI has been mixed. In 2017 Posti et al. compared 93 patients with mTBI to 73 patients with acute orthopedic trauma. Serum was collected on days 1, 2, 3, and 7 after admission. GFAP breakdown products (GFAP-BDPs) were measured using proteomic analyses from Randox Laboratories based on horseradish peroxidase chemiluminescent detection. The authors noted that GFAP was higher in the orthopedic trauma compared to CT-negative mTBI patients on day 1 ( $p=0.026)$, with no differences on subsequent days [15]. Only patients in the orthopedic control group received MRIs, with no correlation being found between abnormal MRI pathology and GFAP serum levels. MRIs were comprehensive including DTI, high-resolution 3D T1 and normal T1/T2 parameters to ensure pathology was not missed. Understandably, this has limited application to the mTBI cohort [15].

In contrast, a small descriptive study by Kou et al. examined nine ED mTBI patients who received blood draws every $6 \mathrm{~h}$ for the first $24 \mathrm{~h}$ post-injury. Mean serum GFAP for mTBI was 10.6 times higher than controls at admission $(0.043 \mathrm{ng} / \mathrm{mL}$ vs. $0.004 \mathrm{ng} / \mathrm{mL} ; p<0.01)$. Multiple imaging modalities were used to determine MRI pathology including DTI. GFAP levels were much higher in patients with hemorrhagic findings on MRI (mean $0.517 \mathrm{ng} / \mathrm{mL}$ ). The authors even describe one case where a small intraventricular hemorrhage near the sublingual gyrus was missed on CT but present on MRI and was associated with a marked increase in GFAP levels that persisted across the $24 \mathrm{~h}$ sampling period (median $4.61 \mathrm{ng} / \mathrm{mL}$ ). However, DTI findings did not correlate with GFAP levels [16]. The Transforming Research and Clinical Knowledge in Traumatic Brain Injury (TRACK-TBI) Pilot analysis by McMahon et al. showed the utility of GFAP breakdown products (GFAP-BDPs) for stratification of TBI severity. 
In 215 patients (mild TBI 83\%, moderate TBI 4\%, severe TBI 12\%), GFAP-BDP levels were associated with increased injury severity on $\mathrm{CT}$ as classified by the Rotterdam Score in both univariate (OR 1.2; $p<0.001$ ) and multivariate (OR 1.13; $p<0.001$ ) analyses [17]. GFAP-BDP values at admission were significantly higher in MRI-positive patients $(1.31 \pm 1.8$ vs. $0.28 \pm 0.57 \mathrm{ng} / \mathrm{mL} ; p<0.001)$. GFAP-BDP levels also predicted the presence of MRI pathology on both univariate $(O R=2.7)$ and multivariate $(O R$ $=3.8$ ) analyses. However, no differences in GFAP-BDPs were seen between CT-/MRI+ and CT-/MRIpatients [17]. Gill et al. analyzed serum GFAP, tau and NF-L in mTBI patients with CT and MRI. GFAP had $\mathrm{AUC}=0.93$ in distinguishing the 277 patients with mTBI from 49 healthy controls on CT and was the only marker able to stratify mTBI patients to CT+ vs. CT - findings. GFAP was also the strongest predictor for CT-/MRI+ findings compared to healthy controls with AUC $=0.803$ and a significant difference between the different patient cohorts (healthy controls: $56.18 \mathrm{pg} / \mathrm{mL}$ (45.98-69.84), CT+/MRI+: 2853 pg/mL (768.2-5724), CT-/MRI+: 2098 pg/mL (253.7-8382), CT-/MRI-: 266.2 pg/mL (101.8-857.2); $p<0.001$ ) [18]. Importantly, these authors used multimodal MRI with high-resolution 3D-T1 images, which may be more sensitive than conventional MR techniques.

In the largest study in CT- mTBI with MRIs to date, Yue et al. demonstrated the relationship between GFAP and CT-/MRI+ patients compared to CT-/MRI-, orthopedic controls, and healthy controls using the 18 center prospective TRACK-TBI study in 2019 [19]. Serum from patients was drawn within $24 \mathrm{~h}$ of TBI and correlated with brain MRI 7-18 days post-injury. A prototype point-of-care immunoassay, capable of generating results within 15 minutes in a controlled setting, was performed at Abbott Laboratories. CT-/MRI+ patients had significantly higher serum GFAP (414.4 pg/mL [IQR 139.3-813.4]) compared to CT-/MRI- (74.0 pg/mL [17.5-214.4]), orthopedic controls (13.1 pg/mL [6.9-20.0]) and healthy controls (8.0 pg/mL [3.0-14.0]). AUC of GFAP for detecting MRI abnormalities in CT- patients ranged from $0.719-0.852$ within the first $24 \mathrm{~h}$ and was most sensitive between 9-16 $\mathrm{h}$ (AUC 0.852) [19]. Furthermore, GFAP was found to be most sensitive for detecting diffuse axonal injury (DAI) on MRI, with AUC 0.903 for distinguishing DAI+ from CT-/MRI- patients, and AUC 0.976 for distinguishing DAI+ from orthopedic controls. The ability to use GFAP to reliably determine the presence of MRI pathology will allow patients who could benefit from advanced imaging to have a higher likelihood of receiving it. Using GFAP in risk stratification and decision-making for targeted intervention can save patients from unnecessary scans while also maximizing the utility of healthcare resources.

\subsection{Ubiquitin Carboxy-Terminal Hydrolase L1 (UCH-L1; 2 Studies)}

UCH-L1 is a protease enzyme that comprises up to $10 \%$ of all neuronal proteins [20]. UCH-L1 can be detected in serum in hours after severe TBI [21]. Two studies that examined the role of plasma GFAP levels also studied plasma UCH-L1, likely related to their different cell of origin. UCH-L1 is a neuronal protein; studies examining the ratio of glial:neuronal proteins (e.g., GFAP:UCH-L1) have shown that this glial:neuronal ratio correlated with the presence of traumatic lesions on CT but not with diffuse injury [20]. For example, Gill et al. measured GFAP and UCH-L1 simultaneously using a Simoa multiplex assay (Quanterix, MA) [18]. While UCH-L1 was unable to discriminate between $\mathrm{CT}-/ \mathrm{MRI}+$ and CT-/MRI-, the authors state that UCH-L1 measurements did not meet internal quality control standards and that these data require further study. Kou et al. reported that UCH-L1 after mTBI was significantly elevated compared to healthy controls $(0.242 \mathrm{vs}$. $0.05 \mathrm{ng} / \mathrm{mL} ; p<0.01)$. However, this did not correlate with the number of MRI lesions [16]. These authors also used a 3 T magnet with tractography so their findings should be sensitive for MR pathology [16]. While UCH-L1 does not seem to be sensitive for MR pathology, its role as a neuronal protein could still be used in a multimodal serum-based risk stratification system given its known increase after TBI and correlation with CT pathologies. 


\subsection{Neurofilament Proteins (NF-L; 3 Studies)}

Neurofilament light (NF-L) protein is a component of axonal intermediate filaments thought to be released following axonal injury. In contrast to other biomarkers, it has a long half-life in vivo of 3 weeks [22], and thus may be of use in TBI patients with delayed or subacute presentation. In a small case series of nine severe TBI patients with DAI, Ljungqvist et al. showed that serum NF-L, measured using a Simoa assay (Quanterix, MA), was 30-fold higher in severe TBI compared to controls with $100 \%$ discrimination [23]. High NF-L correlated with low fractional anisotropy $\left(R^{2}=0.83\right)$-as measured on a 1.5 T MRI by diffusion tensor imaging-and high average diffusivity on DTI $\left(R^{2}=0.79\right)$ [23]. A second study by Al Nimer et al. evaluated the relationship between NF-L and DAI in 182 patients $(\mathrm{mTBI}=8 \%$, moderate $\mathrm{TBI}=21 \%$, severe $\mathrm{TBI}=71 \%$ ) [24]. NF-L levels remained relatively constant from admission to 2 weeks post-injury. A multivariable proportional odds model found that the addition of NF-L to core predictors (age, GCS and pupillary response) improved Nagelkerke pseudo- $R^{2}$ from 0.25 to 0.30 for prediction of outcome based on the Glasgow Outcome Scale (GOS) [24]. No correlation between DAI, as measured by echo planar diffusion MRI, and NF-L levels was noted. Importantly, both studies were skewed towards severe TBI, and understanding whether NF-L can discriminate between MRI findings in the mTBI population remains in need of further study.

A third study by Sandsmark et al. looked at neurofilament heavy chain (NF-H) in 76 traumatic brain injury patients. MRI was used to separate patients into those with traumatic microvascular injury (TVI) defined as diffusion weighted MRI without frank hemorrhage, those with frank hemorrhage (TH) and those with no injury on MRI. NF-H was increased in both TH and TVI groups compared to MRI- group within the first $48 \mathrm{~h}$ following injury [25]. Importantly, NF-H plasma levels remained elevated after $48 \mathrm{~h}$ in the TVI group but not the TH group. These findings show that neurofilament proteins can be a marker for DAI and TVI, and will require future confirmation studies in the larger mTBI population.

\subsection{Tau Protein (2 Studies)}

Tau is a tubulin-associated protein necessary for microtubule polymerization, with numerous physiologic functions including regulation of synaptic transmission and cell cycle regulation. Phosphorylation allows for depolymerization of the tubule bundles, and phosphorylated tau has been linked with various neuropathologic conditions including TBI and Alzheimer's Disease [26]. Recently, Hirad et al. examined the effects of repetitive subconcussive head impacts (RSHIs) by comparing 29 patients with clinically defined mTBI, 38 collegiate football players with helmet-based accelerometers, and 58 healthy controls. The authors hypothesized that both RSHI mTBI patients would have pathologic white matter changes consistent with DAI. DAI was measured using diffusion tensor imaging on a $3 \mathrm{~T}$ magnet in a collegiate football cohort. Traumatic strikes with high rotational acceleration was inversely correlated with fractional anisotropy in midbrain white matter $(r=-0.43$, $p<0.008)$. The number of hits with high linear acceleration was also correlated $(r=-0.32, p<0.049)$. In the mTBI cohort, a similar change in fractional anisotropy in the midbrain was also seen. In 13 of 29 subjects in the mTBI cohort, blood was collected within $72 \mathrm{~h}$ of injury and serum tau was inversely correlated with midbrain fractional anisotropy $(r=-0.60, p<0.033)$ [27].

Tomita et al. examined serum tau in $40 \mathrm{TBI}$ patients grouped into two cohorts using MRI: DAI+ $(n=13)$ and DAI- $(n=27)$. DAI+ patients had significantly higher serum tau $(25.3 \mathrm{vs} .0 .0 \mathrm{pg} / \mathrm{mL}$, $p=0.03)$ and the receiver operating statistic of serum tau at $1.5 \mathrm{pg} / \mathrm{mL}$ showed good sensitivity $(74.1 \%)$ and specificity (69.2\%) for diagnosis of DAI on diffusion-weighted imaging (DWI). Unfortunately, plasma tau was unable to predict unfavorable outcome (GOS) $(p=0.19)$ [28]. The ability for tau to correlate with fractional anisotropy changes and DAI reflect its promise as a serum biomarker; standardized MR techniques may help further improve the prognostic utility of tau protein. 


\subsection{Alpha-Synuclein ( $\alpha$-Synuclein; 1 Study)}

Beyond the classification of axonal versus neuronal injury, specific biomarkers may allow for identification of altered neural connectivity. $\alpha$-Synuclein is a presynaptic neuronal protein seen in various forms of dementia. In 2019 Ye et al. examined serum $\alpha$-synuclein in 52 mTBI patients and 47 healthy controls using a multiplex assay (Luminex Corp, Austin, TX, USA) [29]. Patients were evaluated with functional MRI and comprehensive neuropsychological testing. MTBI patients were divided into high and low $\alpha$-Synuclein groups based on biomarker levels in healthy controls. Low $\alpha$-synuclein levels were associated with higher post-concussional (PCS; $\beta=-0.333, p=0.013$ ) and depression symptoms $(\beta=-0.311, p=0.022)$. In default mode network studies, higher $\alpha$-synuclein correlated with greater functional connectivity in the left anterior cingulate and ventral medial prefrontal cortices $(p<0.05)$. As $\alpha$-synuclein is a presynaptic neuronal protein present in dementia, this finding may seem paradoxical. The authors suggest that the higher $\alpha$-synuclein levels in patients with greater connectivity and better outcomes may be due to a compensatory mechanism whereas lower levels are due to lack of compensation [29].

\subsection{Alpha-Amino-3-Hydroxy-5-Methyl-4-Isoxazolepropionic Acid Receptor Peptide (AMPAR; 1 Study)}

AMPAR is a product of the proteolytic degradation of AMPA receptors, which provide glutamatergic synaptic transmission. Neural networks can develop excitotoxic activity in TBI, resulting in large glutamate release and AMPAR upregulation [30-32]. Disturbances in glutamate synaptic transmission during concussion may be measurable with plasma AMPAR. In 2013, Dambinova et al. studied 84 athletes and 40 nonathletes pre- and post-collegiate sport season [33]. AMPAR was analyzed using magnetic antibody precipitation with light absorbance quantification. Outcomes were assessed using the ImPACT neurocognitive battery. Thirty-three athletes had concussions post-season and were age- and gender-matched to the other 91 controls without concussion. In general, the concussed group had higher AMPAR ( $2.15 \mathrm{ng} / \mathrm{mL}(0.96-8.49))$ vs. nonathletes $(0.19 \mathrm{ng} / \mathrm{mL}(0.04-0.40))$. However, three subjects with concussion had low AMPAR $(0.20-0.36 \mathrm{ng} / \mathrm{mL})$ and seven non-athletes had elevated AMPAR $(0.44-1.10 \mathrm{ng} / \mathrm{mL})$. At a cutoff of $0.4 \mathrm{ng} / \mathrm{mL}$, AMPAR had a sensitivity of $91 \%$ and specificity of $92 \%$ for detecting concussions. The three subjects who received MRIs had multiple concussions, high AMPAR, and decreased ImPACT scores. MRI included T1 and T2 FLAIR images which may be less sensitive to axonal shear than diffusion weighted imaging. Of these, two had resolution of symptoms over 3 weeks, with declining AMPAR levels, without evidence of axonal shear on MRI. The third patient continued to have high AMPAR levels $(5.2 \mathrm{ng} / \mathrm{mL}) 6$ months post-injury, with spots of microhemorrhage in deep brain structures and changes in high convexity white matter [33]. This study highlights the utility of drawing longitudinal AMPAR levels as it may correlate with persistent TBI pathology. 
Table 1. Summary of Included Studies.

\begin{tabular}{|c|c|c|c|c|c|c|c|}
\hline \multicolumn{8}{|c|}{$S 100 B$} \\
\hline Author and Year & Study Type & $N$ & $\begin{array}{l}\text { MRI Acquisition } \\
\text { Parameters }\end{array}$ & Description & $\begin{array}{l}\text { Outcome } \\
\text { Measures }\end{array}$ & $\begin{array}{l}\text { Timing of Serum } \\
\text { Sampling }\end{array}$ & Results \\
\hline $\begin{array}{l}\text { Ingebrigtsen et al., } \\
1999\end{array}$ & $\begin{array}{l}\text { Prospective } \\
\text { Cohort }\end{array}$ & 50 TBI & $\begin{array}{l}0.5 \text { T magnet; } \\
\text { T1/T2 FLAIR }\end{array}$ & $\begin{array}{l}\text { Validation of } \mathrm{S} 100 \text { as a serum } \\
\text { biomarker for brain injury. }\end{array}$ & Serum S100B & $\begin{array}{l}\text { On admission and } \\
12 \mathrm{~h} \text { post-injury }\end{array}$ & $\begin{array}{l}\text { In total, } 14 / 50(28 \%) \text { of patients had detected serum S100 } \\
\text { (mean } 0.4 \mathrm{ug} / \mathrm{L} \pm 0.3) \text {, with levels being highest } \\
\text { immediately after injury and declining each hour after. } \\
\text { S100B not detectable in } 36 \% \text { of patients after } 6 \mathrm{~h} \text { of } \\
\text { initial detection. There were five MRI+ patients with } \\
\text { brain contusions- of which have had elevated S100B. }\end{array}$ \\
\hline $\begin{array}{c}\text { Linsenmaier et al., } \\
2016\end{array}$ & $\begin{array}{l}\text { Prospective } \\
\text { Cohort }\end{array}$ & 41 TBI & $\begin{array}{c}\text { 1.5 T magnet; } \\
\text { T1/T2; GRE; DWI }\end{array}$ & $\begin{array}{l}\text { Feasibility study of S100B as } \\
\text { biomarker in mTBI with MRI. }\end{array}$ & $\begin{array}{c}\text { Serum S100B CT; } \\
\text { MRI }\end{array}$ & $\begin{array}{l}\text { Hourly, until } 12 \mathrm{~h} \\
\text { post-injury }\end{array}$ & $\begin{array}{l}\text { In total, } 27 / 32(84 \%) \text { of patients with very high serum } \\
\text { S100B serum were MRI-negative and } 4 / 27 \text { with high } \\
\text { S100B were CT+. Five MRI+ patients had elevated } \\
\text { S100B. S100B sensitivity } 100 \% \text { with specificity of } 81 \% \text {. }\end{array}$ \\
\hline Marchi et al., 2013 & $\begin{array}{l}\text { Prospective } \\
\text { Cohort }\end{array}$ & 15 athletes & 3 T magnet; DTI & $\begin{array}{l}\text { Serum S100B in college football } \\
\text { players with MRI. }\end{array}$ & $\begin{array}{l}\text { Serum S100B; MRI; } \\
\text { neurocognitive } \\
\text { tests }\end{array}$ & $\begin{array}{l}\text { Before and after } \\
\text { sports season }\end{array}$ & $\begin{array}{l}\text { S100B post-game was elevated }(0.51 \pm 0.05 \mathrm{ng} / \mathrm{mL}) \\
\text { compared to baseline. Higher number of impacts } \\
\text { correlated with increased S100B }(p=0.03) \text {. High S100B } \\
\text { auto-antibodies correlated }(r=0.58, p=0.07) \text { with errors } \\
\text { in impulse control }\end{array}$ \\
\hline Oh et al., 2007 & $\begin{array}{l}\text { Prospective } \\
\text { Cohort }\end{array}$ & 101 ТВI & unspecified & $\begin{array}{l}\text { Serum S100B in patients } \\
\text { admitted to EDt for TBI with } \\
\text { CT/MRI. }\end{array}$ & $\begin{array}{l}\text { Serum S100B; CT; } \\
\text { MRI }\end{array}$ & On admission & $\begin{array}{c}\text { Healthy controls had serum S100B } 0.080 \mathrm{ug} / \mathrm{L} \\
(0.049-0.094) \text { compared to } 0.150 \mathrm{ug} / \mathrm{L}(0.088-0.358) \text { in } \\
\text { acute TBI. 66/101 CT/MRI+ patients had higher S100B } \\
\text { compared to CT/MRI-negative }(p=0.028) \text {. AT cutoff of } \\
0.105 \mathrm{ug} / \mathrm{L} \text {, sensitivity } 84.8 \% \text { and specificity } 74.3 \% \text { for } \\
\text { detecting acute TBI. }\end{array}$ \\
\hline Thelin et al., 2014 & $\begin{array}{l}\text { Retrospective } \\
\text { Cohort }\end{array}$ & 199 TBI & $\begin{array}{l}\text { T1/T2; FLAIR; } \\
\text { GRE }\end{array}$ & $\begin{array}{l}\text { An analysis of serum increases } \\
\text { in S100B levels post-TBI in } \\
\text { addition to pathological } \\
\text { imaging. }\end{array}$ & $\begin{array}{l}\text { Serum S100B; CT; } \\
\text { MRI }\end{array}$ & $\begin{array}{c}\text { Three samples, } \\
\text { with } 1 / 3 \text { taken }>48 \\
\text { h after injury }\end{array}$ & $\begin{array}{c}\text { Secondary increases in S100B with a cutoff of } 0.05 \mathrm{ug} / \mathrm{L} \\
\text { had sensitivity } 80 \% \text { and specificity } 89 \% \text {, while cutoff of } \\
0.5 \mathrm{ug} / \mathrm{L} \text { has sensitivity } 16 \% \text { and specificity } 98 \% \text { for } \\
\text { imaging findings of TBI. }\end{array}$ \\
\hline \multicolumn{8}{|c|}{ GFAP, UCH-L1 } \\
\hline Author and Year & Study Type & $N$ & Parameters & Description & Measures & Sampling & Results \\
\hline Gill et al., 2018 & $\begin{array}{l}\text { Prospective } \\
\text { Cohort }\end{array}$ & 277 mTBI & $\begin{array}{l}\text { T1/T2; FLAIR; } \\
\text { 3D-T1; DTI }\end{array}$ & $\begin{array}{l}\text { Plasma biomarkers were } \\
\text { correlated with MRI data. }\end{array}$ & $\begin{array}{l}\text { Plasma GFAP; tau; } \\
\text { NFL; UCH-L1 }\end{array}$ & $\begin{array}{l}\text { Within } 48 \mathrm{~h} \text { of } \\
\text { injury }\end{array}$ & $\begin{array}{l}\text { mTBI had higher plasma GFAP, tau, and NF-L }(p<0.01) \\
\text { Patients with MRI findings had significantly higher } \\
\text { concentrations of plasma GFAP, tau, and NF-L } \\
\text { compared to MRI- and CT- mTBI patients }(p<0.05) \text {. }\end{array}$ \\
\hline
\end{tabular}


Table 1. Cont

\begin{tabular}{|c|c|c|c|c|c|c|c|}
\hline Kou et al., 2013 & $\begin{array}{l}\text { Prospective } \\
\text { Cohort }\end{array}$ & Nine mTBI & $\begin{array}{l}3 \text { T magnet; T1/T2; } \\
\text { GRE; FLAIR; DTI }\end{array}$ & $\begin{array}{l}\text { Feasibility testing of the } \\
\text { utilization of both biomarkers } \\
\text { and MRI to detect mTBI. }\end{array}$ & $\begin{array}{l}\text { Serum UCH-L1 } \\
\text { and GFAP levels; } \\
\text { MRI data }\end{array}$ & $\begin{array}{l}\text { Within } 6 \mathrm{~h} \text { of } \\
\text { injury, and q6 h } \\
\text { until } 24 \mathrm{~h} \\
\text { post-injury }\end{array}$ & $\begin{array}{l}\text { UCH-L1 (4.9-fold) and GFAP (10.6-fold) were elevated } \\
\text { on admission in comparison to lab reference values. } \\
\text { Patients with intracranial hemorrhages had higher } \\
\text { GFAP compared to non-hemorrhage }(p=0.002) \text {. } \\
\text { GFAP/UCH-L1 did not associate with MRI findings. }\end{array}$ \\
\hline $\begin{array}{l}\text { McMahon et al., } \\
2015\end{array}$ & $\begin{array}{l}\text { Prospective } \\
\text { Cohort }\end{array}$ & 215 TBI & unspecified & $\begin{array}{l}\text { Plasma GFAP-BDPs were used } \\
\text { to predict CT/MRI+ TBI. }\end{array}$ & $\begin{array}{c}\text { Plasma } \\
\text { GFAP-BDPs; MRI }\end{array}$ & $\begin{array}{l}\text { Within } 24 \mathrm{~h} \text { of } \\
\text { injury }\end{array}$ & $\begin{array}{c}\text { In total, } 35 \% \text { had evidence of TBI on MRI }(n=21) \text {. On } \\
\text { admission, MRI+ patients had significantly higher } \\
\text { GFAP-BDPs }(1.3 \pm 1.8 \mathrm{ng} / \mathrm{m} ; p=0.001 \mathrm{~L}) \text { than MRI- } \\
(0.28 \pm 0.57) \text {. Plasma concentrations of GFAP-BDPs } \\
\text { predicted evidence of MRI pathology (OR 2.7; } 95 \% \mathrm{CI} \\
1.2-5.7) \text {. }\end{array}$ \\
\hline Posti et al., 2017 & $\begin{array}{l}\text { Prospective } \\
\text { Cohort }\end{array}$ & $94 \mathrm{mTBI}$ & $\begin{array}{l}3 \text { T magnet; T1/T2; } \\
\text { FLAIR; DTI; 3D-T1 }\end{array}$ & $\begin{array}{l}\text { Plasma GFAP, UCH-L1 in TBI } \\
\text { were compared to orthopedic } \\
\text { trauma. }\end{array}$ & $\begin{array}{l}\text { Serum GFAP and } \\
\text { UCH-L1; CT/MRI }\end{array}$ & $\begin{array}{l}\text { On days } 1,2,3,7 \\
\text { post-admission }\end{array}$ & $\begin{array}{l}\text { None in the mTBI group showed signs of TBI on MRI. } \\
\text { GFAP was initially higher in acute orthopedic trauma } \\
\text { compared to acute CT-/MRI- mTBI }(p=0.026) \text { with no } \\
\text { difference days later. No difference in UCH-L1. }\end{array}$ \\
\hline Yue et al., 2019 & $\begin{array}{l}\text { Prospective } \\
\text { Cohort }\end{array}$ & $\begin{array}{l}450 \text { TBI, } 122 \\
\text { orthopedic and } 207 \\
\text { healthy controls }\end{array}$ & $\begin{array}{l}\text { T1/T2; FLAIR; } \\
\text { GRE }\end{array}$ & $\begin{array}{l}\text { Patients with negative initial } \\
\mathrm{CT} \text {, with MRI at } 7-18 \text { days, vs. } \\
\text { orthopedic trauma controls and } \\
\text { healthy controls. }\end{array}$ & $\begin{array}{c}\text { Plasma GFAP and } \\
\text { MRI }\end{array}$ & $\begin{array}{l}\text { Within } 24 \mathrm{~h} \text { of } \\
\text { injury }\end{array}$ & $\begin{array}{l}\text { CT-/MRI+ (414.5 pg/mL; } p<0.001) \text { patients had the } \\
\text { highest plasma GFAP, compared to CT-/MRI- }(74.0) \text {, } \\
\text { orthopedic trauma (13.1) and healthy controls }(8.0) \text {. } \\
\text { AUC for discriminating MRI+ in CT- population was } \\
\text { 0.852. GFAP was notably elevated for DAI on MRI, } \\
\text { compared to other types of intracranial pathology. }\end{array}$ \\
\hline \multicolumn{8}{|c|}{ Tau } \\
\hline Author and Year & Study Type & $N$ & $\begin{array}{l}\text { MRI Acquisition } \\
\text { Parameters }\end{array}$ & Description & $\begin{array}{l}\text { Outcome } \\
\text { Measures }\end{array}$ & $\begin{array}{l}\text { Timing of Serum } \\
\text { Sampling }\end{array}$ & Results \\
\hline Hirad et al., 2019 & $\begin{array}{l}\text { Retrospective } \\
\text { Cohort }\end{array}$ & $29 \mathrm{mTBI}$ & $\begin{array}{l}3 \text { T magnet; 3D-T1; } \\
\text { DTI }\end{array}$ & $\begin{array}{l}\text { NCAA contact sport athletes } \\
\text { with mTBI were monitored for } \\
\text { concussion with plasma } \\
\text { sampling and cognitive testing } \\
\text { pre-/post-season. }\end{array}$ & $\begin{array}{c}\text { White matter } \\
\text { structural integrity } \\
\text { using FA pre- and } \\
\text { post-season, vs. } \\
\text { age-matched } \\
\text { controls, } \\
\text { correlation } \\
\text { between plasma } \\
\text { tau and midbrain } \\
\text { FA }\end{array}$ & $\begin{array}{l}\text { Before and after } \\
\text { sports season; } \\
\text { mTBI patients had } \\
\text { venipuncture } \\
\text { within } 72 \mathrm{~h} \text { of } \\
\text { injury }\end{array}$ & $\begin{array}{l}\text { FA reduced in the right midbrain in concussed athletes } \\
\text { compared to controls. Of } 13 / 29 \text { mTBI patients with } \\
\text { blood samples, Tau was inversely related to midbrain } \\
\text { FA ( } r=-0.60, p=0.033) \text {. }\end{array}$ \\
\hline Tomita et al., 2019 & $\begin{array}{l}\text { Prospective } \\
\text { Observational }\end{array}$ & 40 TBI & T2 FLAIR; DWI & $\begin{array}{c}\text { TBI patients with acute } \\
\text { symptoms }<6 \mathrm{~h} \text { and patients } \\
\text { with MRI evidence of DAI on } \\
\text { T2WI/DWI regardless of } \\
\text { symptoms. }\end{array}$ & $\begin{array}{l}\text { Serum tau in DAI } \\
\text { vs. non-DAI } \\
\text { groups; sensitivity } \\
\text { and specificity of } \\
\text { Tau for DAI }\end{array}$ & $\begin{array}{l}\text { Within } 6 \mathrm{~h} \text { of } \\
\text { injury }\end{array}$ & $\begin{array}{l}\text { All patients had high intensity areas on MRI within } \\
\text { corpus callosum, brainstem and cerebrum with } \\
\text { T2WI/DWI. Tau was higher in DAI }(25.3 \mathrm{pg} / \mathrm{mL} ; 0-99.1) \\
\text { vs. non-DAI }(0.0 \mathrm{pg} / \mathrm{mL} ; 0-44.4) \text {. At cutoff } 1.5 \mathrm{pg} / \mathrm{mL} \text {, } \\
\text { sensitivity } 74.1 \% \text { and specificity } 69.2 \% \text { for DAI. }\end{array}$ \\
\hline
\end{tabular}


Table 1. Cont.

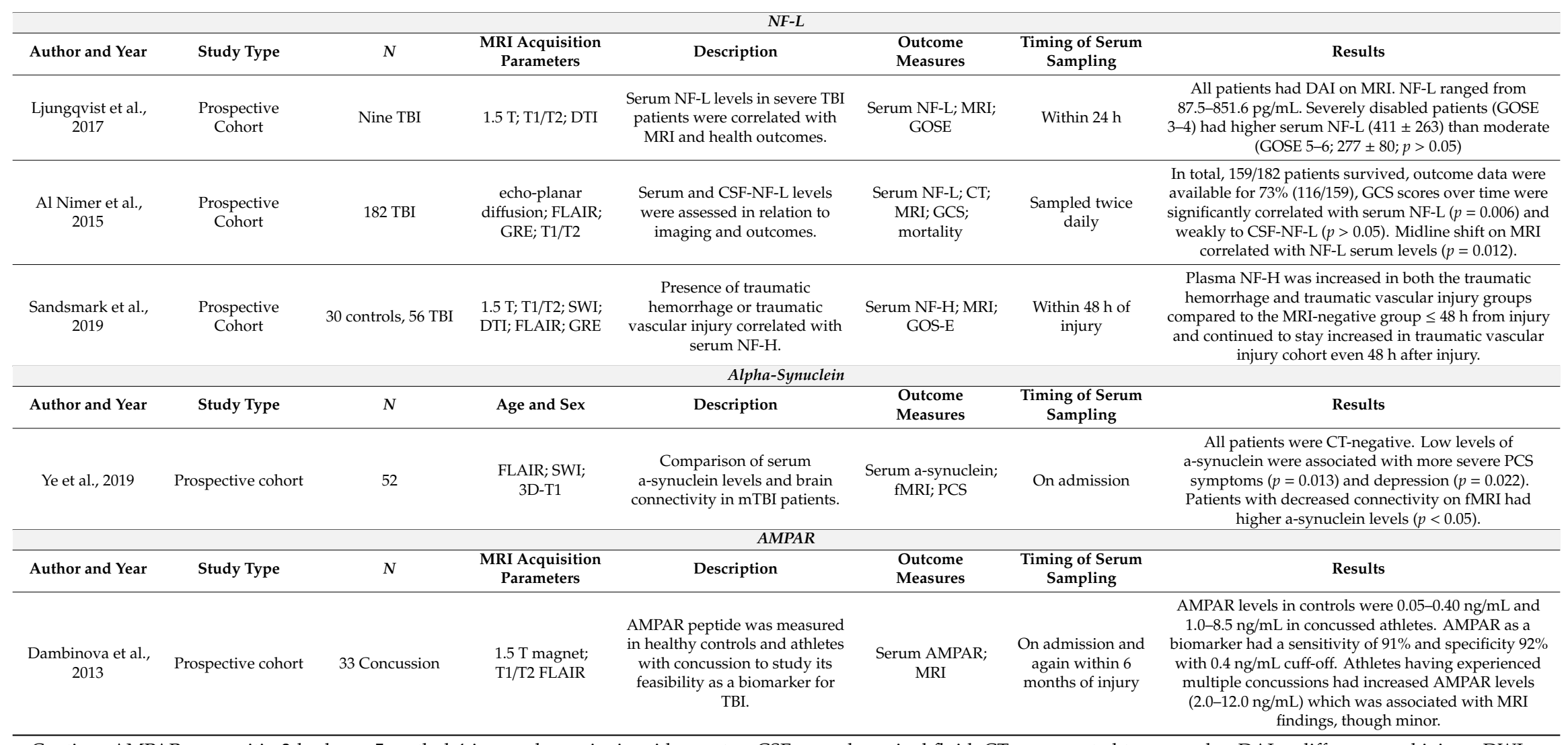

Caption: AMPAR = a-amitio-3-hydroxy-5-methyl-4-isoxazolepropionic acid receptor; CSF = cerebrospinal fluid; CT = computed tomography; DAI = diffuse axonal injury; DWI = diffusion-weighted imaging; ED = emergency department; FA = fractional anisotropy; GFAP = glial fibrillary acidic protein; GFAP-BDP = glial fibrillary acidic protein breakdown products; GOS = Glasgow Outcome Scale; GOSE = Glasgow Outcome Scale-Extended; MRI = magnetic resonance imaging; NCAA = National Collegiate Athletic Association; NF-L = neurofilament light chain; PCS = post-concussional symptoms; T2WI = T2-weighted imaging; TBI = traumatic brain injury; UCH-L1 = ubiquitin carboxyl-terminal hydrolase L1; GRE = gradient echo; DTI = diffusion tensor imaging; 3D-T1 = 3-dimensional T1; DTI = Diffusion Tractography Imaging; FLAIR = Fluid Attenuated Infusion Recovery. 


\section{Discussion}

In the U.S. alone, 1.7-2.0 million TBI cases are documented annually with mTBI cases comprising over $85 \%$ of total cases [34,35]. The overall incidence is likely much higher due to patients who do not reach care and/or are not included in national statistics. Diagnosis of TBI presents a unique clinical challenge as the disease presents heterogeneously, and alterations in consciousness can be due to a number of pathophysiological mechanisms. Proper treatment of TBI relies upon proper diagnosis and clear understanding of intracranial pathology.

\subsection{Relevance of MRI-Based TBI Diagnosis and Rationale for Serum Biomarker Use}

Although MRI is more sensitive than CT for detecting changes in virtually all post-traumatic lesions except for acute fractures or hemorrhage, the ability to obtain routine MRIs is limited by resource availability and cost. For this reason, the American College of Emergency Physicians (ACEP)/Centers for Disease Control (CDC) guidelines for mTBI do not recommend MRI for the evaluation of acute TBI [5]. Recent data, however, show that nearly $29 \%$ of mTBI are CT-occult [36]. This constitutes one reason that over time, $\mathrm{mTBI}$ patients who have similar acute presentations can either achieve full functional recovery or can have persistent neuropsychiatric sequelae and functional deficits [36].

While MRI may help direct resources to this undertreated patient population, a few challenges do exist. Namely standardization due to different magnets, acquisition parameters, and processing algorithms means the generalizability of MRI findings may be limited [37,38]. While MRI can help direct resources to this patient population; standardized guidelines for MRI acquisition are needed to ensure that data between sites are readily comparable.

The importance of MRI findings, especially in mTBI patients with normal CT, was highlighted by Yuh et al. in 2013. MRI pathology in the form of contusions or DAI in CT-negative mTBI were independently associated with poorer 3 month functional outcomes on GOSE [36]. Based on CT scans alone, these patients would be considered "uninjured" with few to no standard follow-up instructions [39]. High rates of post-traumatic stress disorder and major depressive disorder following mTBI are associated with CT-occult MRI findings [40]. This further highlights the need for targeted utilization of MRI for determining which mTBI patients are at elevated risk and who should be prioritized for healthcare surveillance and follow up [41,42].

Use of a circulating biomarker capable of diagnosing CT-occult mTBI could significantly improve TBI diagnosis. The smaller retrospective studies reported in this review have few MRIs ( 9\%) [33]. These low rates even in clinical trials, such as in TRACK-TBI Pilot $(\sim 40 \%)$, show the barriers to access for MRI [43]. Cost-effectiveness data for the use of a biomarker for screening show that a biomarker assay should cost less than $\$ 308.96$ to be more effective than standard CT in TBI patients [44]. It stands to reason that the cost-effectiveness cutoff for MRI is much higher. Comparatively, a study in Sweden showed the cost of serum sampling of S100B is only 21 euros [45]. Together, these data show the potential for both cost savings and improved diagnostic accuracy.

Biomarker studies have had marked success in discriminating intracranial findings on CT with AUCs of $>0.90$. This success led to U.S. Food and Drug Administration (FDA) clearance of a composite biomarker assay measuring acute GFAP and UCHL-1 levels in blood for differentiation of patients with normal versus abnormal CT including the pivotal clinical trial ALERT-TBI with 1977 TBI patients with initial GCS 9-15 [46-49]. Serum S100B has been incorporated into Scandinavian TBI guidelines in triaging mTBI patients who may need CT [50]. Unfortunately, validation of biomarkers for MRI remains a challenge largely due to the large cost associated with MRI. Moreover, since MRI is not part of the current standard of care clinical TBI guidelines, studies to date remain sparse [5]. The final hurdle with using serum biomarkers to stratify MRI findings is due to the various temporal cascades of different serum biomarkers, related to cell type of origin and inflammatory responses. Acute biomarkers, e.g., neuronal/axonal injury markers (UCH-L1), blood-brain barrier breakdown markers (S100B) and reactive gliosis or glial injury markers (ie. GFAP), peak within hours of injury. Subacute markers, such as NF-L may peak within days to weeks. Chronic biomarkers such as Tau/phosphorylated Tau may 
peak in weeks to months and signify neurodegenerative changes [51]. These data show the difficulties in defining an optimal timeframe and serum biomarker combination that can be of use in stratifying TBI patients according to MRI pathology.

This challenge is best demonstrated by the diagnostic biomarker S100B. The data assessing the utility of S100B for diagnosis are mixed. S100B levels are shown to return to baseline within $7 \mathrm{~h}$ of injury, creating a short window for serum acquisition $[7,8]$. This fact may underlie the heterogeneity in the published relationships between S100B levels and neuroimaging findings. Previous studies have failed to link BBB dysfunction (assessed via dynamic contrast MRI) with serum S100B levels [52]. Studies by Romner, Oh, Linsemaier, and Ingebritsen all show that low/undetectable serum S100B $(<0.2 \mathrm{ug} / \mathrm{L})$ has high negative predictive value for neuroimaging pathology, and thus rarely have true pathologic findings on CT or MRI [7-9,11]. This finding shows S100B's utility in preventing unnecessary CTs, but underscores its limitation in determining MRI pathology.

\subsection{GFAP Has High Diagnostic Potential for MRI}

Of the biomarkers currently under consideration, the one with the greatest potential is GFAP. GFAP has already received FDA approval to evaluate intracranial injury given the high predictive capacity for CT findings [17]. The 18 center TRACK-TBI study with interim analysis of 450 CT- mTBI patients with MRIs, 122 orthopedic controls and 209 healthy controls serves as preliminary Phase III evidence of the ability for GFAP to distinguish between CT-/MRI+ and CT-/MRI- TBI [19]. Although still awaiting validation from the full TRACK-TBI cohort, Yue et al. show that GFAP collected within $24 \mathrm{~h}$ post-injury had AUC of 0.777 for discriminating CT-/MRI+ from CT-/MRI-, which rises to 0.852 in the 9-16 h cohort [19]. Perhaps even more striking, subgroup analysis showed that GFAP was able to discriminate DAI+ from CT-/MRI- patients with AUC $=0.903$ [19]. These data are supported by prior smaller studies, including Gill et al. which showed that GFAP-BDPs could be used to discriminate between CT-/MRI+ and healthy controls, and by Kou et al. which showed increased GFAP levels in CT-/MRI+ patients with intraventricular hemorrhage [16,18]. These findings show the promise of serum GFAP as a diagnostic TBI biomarker, and in evaluating suspicion for specific intracranial pathologies on MRI.

\subsection{Tau Has Possible Diagnostic Potential for MRI}

Tau also shows promise as a serum biomarker of intracranial pathology on MRI. As a marker of neurodegeneration, Tau persists in circulation for weeks to months following TBI [28]. For this reason, serum Tao monitoring can enable serial analyses with post-acute MRIs for continued follow up. Tomita et al. showed that Tau is elevated in cases of DAI and has a sensitivity of 74.1 for diagnosing DAI [28]. Hirad et al. showed that high serum Tau correlated with lower fractional anisotropy and hence disrupted white matter [27]. Moreover, Tau levels correlated with the number of strikes in concussed athletes, and thus may be a potential marker that is dose-dependent and congruent with the clinical reality of multiple impacts [27]. Early studies from the TRACK-TBI pilot cohort have also shown that phospho-Tau shows good discriminability for chronic TBI versus healthy controls with an AUC of 0.963-1.00 [53]. 


\subsection{Biomarkers in Need of Further Research for Diagnostic Potential on MRI}

NF-L has potential for risk stratification beyond the acute injury window. As it persists for up to 3 weeks in serum, it provides a subacute measure that may correlate with both MRI and long term outcomes. While Ljungvist et al. showed that high NF-L levels correlated with lower fractional anisotropy, their study was small (limited to nine patients) [23]. Other larger studies, such as the one by Al Nimer have not demonstrated similar findings showing no correlation between DAI and NF-L levels. Although the data are mixed, the ability for a biomarker to predict MRI changes in the subacute or chronic phase following TBI warrants further investigation [24].

Two emerging markers for MRI abnormalities remain in need of larger confirmatory studies. $\alpha$-Synuclein may be a marker for disrupted connectivity and reduced fractional anisotropy. Ye et al. showed that in TBI patients, high $\alpha$-synuclein is associated with greater functional connectivity; this paradoxical finding may be related to a compensatory mechanism following brain injury that utilizes this presynaptic neuronal protein. Importantly, the low levels of $\alpha$-synuclein not only predicted decreased functional connectivity, but also greater post-concussional symptoms [29]. This shows that $\alpha$-synuclein may be important for an outcomes-based treatment approach. The second marker of interest is AMPAR, a marker of glutamatergic dysregulation. While patients with multiple concussions and increased symptomatology also had increased circulating AMPAR, only one had verifiable MRI abnormality [33]. These studies parallel to results from GFAP, where CT-/MRI- TBI had higher circulating GFAP (mean $74 \mathrm{pg} / \mathrm{mL}$ ) compared to orthopedic $(13 \mathrm{pg} / \mathrm{mL})$ and healthy controls $(8 \mathrm{pg} / \mathrm{mL})$, suggesting that even CT-/MRI- patients may have subclinical damage to the brain after TBI [19].

\section{Limitations}

TBI studies to date on biomarkers and MRI remain low in number and sample size and are often secondary endpoints to CT-based studies, thus constituting mostly Level III/IV evidence. Thresholds for detection of MRI abnormalities must be established for biomarkers of interest, with GFAP at the forefront in near-term potential for diagnosis [19]. A key factor beyond control in this review was the different imaging parameters in different studies. Since detection of MRI abnormalities depends on magnet strength, imaging parameters and post-processing, standardization of imaging parameters through consensus protocols can help improve standardization of the serum biomarker findings across larger patient populations. Many serum biomarkers correlated with axonal injury and the detectability of axonal injury dramatically differs whether structural MRI or advanced tractography is being used. This highlights the need for further large-scale multi-institution studies for the evaluation of the utility of diagnostic serum biomarkers in MRI.

Relevant temporal cascades of biomarkers of interest also need to be established with MRIs. In the current research environment, MRIs are often acquired much later than the initial blood draw and thus generalizability is limited. However, this argues for the case of using a sensitive biomarker for triage to subacute or outpatient MRI after mTBI. Furthermore, in most studies to date, biosamples were collected with different post-injury times and their results aggregated. As different biomarkers have different half-lives in circulation, biomarker values and their correlation with imaging may differ depending on time of draw. As stated earlier, MRI is not currently standard of care for TBI [5]. However, given the recent evidence on biomarker correlates of CT-occult injuries, the next TBI guidelines may benefit from inclusion of MRI in targeted mTBI subpopulations. While out of scope of the current paper, relevant biomarkers for prognosis after TBI constitutes another imminent future direction. 


\section{Conclusions}

Under the current standard of care, TBI cases without CT abnormalities are discharged with return precautions but may have subclinical injuries and persistent functional symptoms. An acute circulating biomarker able to discriminate MRI abnormalities will be critical to the diagnosis of CT-occult TBI. MRI in trauma and acute care is a limited resource and a biomarker with high discrimination for MRI+ intracranial injury can triage patients who may benefit from outpatient MRI, increased surveillance and/or post-acute follow up with a TBI specialist. Of current markers in literature, the glial marker GFAP has shown high potential for diagnostic efficacy for MRI+ intracranial injury (notably for DAI), and awaits Phase III validation studies. The neurodegenerative marker Tau shows promise in detecting DAI and disrupted functional connectivity. Thresholds for detection of MRI abnormalities, and considerations for temporal cascades in their release after blood brain barrier disruption, must be established for biomarkers of interest.

Author Contributions: Conceptualization: J.K.Y., P.S.U., and K.K.W.W.; Methodology: J.K.Y., P.S.U., and K.K.W.W.; Formal Analysis: J.K.Y. and P.S.U.; Investigation: J.K.Y., P.S.U., L.N.A., H.D., and K.K.W.W.; Resources, X.X.; Data Curation: J.K.Y., P.S.U., L.N.A., and H.D.; Writing: J.K.Y., P.S.U., L.N.A., H.D., and K.K.W.W.; Supervision: J.K.Y., P.S.U., and K.K.W.W.; Project Administration: J.K.Y., P.S.U., and K.K.W.W. All authors have read and agreed to the published version of the manuscript.

Funding: This research received no external funding.

Conflicts of Interest: K.K.W.W. is a shareholder of both Gryphon Bio, Inc., and Banyan Biomarkers, Inc.

\section{References}

1. Taylor, C.A.; Bell, J.M.; Breiding, M.J.; Xu, L. Traumatic brain injury-related emergency department visits, hospitalizations, and deaths - United States, 2007 and 2013. MMWR Surveill. Summ. 2017, 66, 1-16. [CrossRef]

2. Faul, M.; Coronado, V. Epidemiology of Traumatic Brain Injury. Handb. Clin. Neurol. 2015, 127, 3-13. [PubMed]

3. Papa, L.; Edwards, D.; Ramia, M. Exploring serum biomarkers for mild traumatic brain injury. In Brain Neurotrauma: Molecular, Neuropsychological, and Rehabilitation Aspects; Kobeissy, F.H., Ed.; CRC Press/Taylor \& Francis: Boca Raton, FL, USA, 2015; ISBN 9781466565982.

4. Rabinowitz, A.R.; Levin, H.S. Cognitive sequelae of traumatic brain injury. Psychiatr. Clin. N. Am. 2014, 37, 1-11. [CrossRef] [PubMed]

5. Jagoda, A.S.; Bazarian, J.J.; Bruns, J.J., Jr.; Cantrill, S.V.; Gean, A.D.; Howard, P.K.; Ghajar, J.; Riggio, S.; Wright, D.W.; Wears, R.L.; et al. Clinical policy: Neuroimaging and decisionmaking in adult mild traumatic brain injury in the acute setting. Ann. Emerg. Med. 2008, 52, 714-748. [CrossRef] [PubMed]

6. Herrmann, M.; Curio, N.; Jost, S.; Wunderlich, M.T.; Synowitz, H.; Wallesch, C.W. Protein S-100B and neuron specific enolase as early neurobiochemical markers of the severity of traumatic brain injury. Restor. Neurol. Neurosci. 1999, 14, 109-114. [PubMed]

7. Ingebrigtsen, T.; Waterloo, K.; Jacobsen, E.A.; Langbakk, B.; Romner, B. Traumatic brain damage in minor head injury: Relation of serum S-100 protein measurements to magnetic resonance imaging and neurobehavioral outcome. Neurosurgery 1999, 45, 468-475; discussion 475-476. [CrossRef] [PubMed]

8. Romner, B.; Ingebrigtsen, T.; Kongstad, P.; Børgesen, S.E. Traumatic brain damage: Serum S-100 protein measurements related to neuroradiological findings. J. Neurotrauma 2000, 17, 641-647. [CrossRef]

9. Oh, E.-J.; Kim, Y.-M.; Jegal, D.-W.; Kahng, J.; Park, Y.-J.; Han, K. Diagnostic value of Elecsys S100 as a marker of acute brain injury in the emergency department. J. Clin. Lab. Anal. 2007, 21, 387-392. [CrossRef]

10. Thelin, E.P.; Nelson, D.W.; Bellander, B.-M. Secondary peaks of S100B in serum relate to subsequent radiological pathology in traumatic brain injury. Neurocrit. Care 2014, 20, 217-229. [CrossRef]

11. Linsenmaier, U.; Wirth, S.; Kanz, K.-G.; Geyer, L.L. Imaging minor head injury (MHI) in emergency radiology: MRI highlights additional intracranial findings after measurement of trauma biomarker S-100B in patients with normal CCT. Br. J. Radiol. 2016, 89, 20150827. [CrossRef]

12. Marchi, N.; Bazarian, J.J.; Puvenna, V.; Janigro, M.; Ghosh, C.; Zhong, J.; Zhu, T.; Blackman, E.; Stewart, D.; Ellis, J.; et al. Consequences of repeated blood-brain barrier disruption in football players. PLOS ONE 2013, 8, e56805. [CrossRef] [PubMed] 
13. Papa, L.; Silvestri, S.; Brophy, G.M.; Giordano, P.; Falk, J.L.; Braga, C.F.; Tan, C.N.; Ameli, N.J.; Demery, J.A.; Dixit, N.K.; et al. GFAP out-performs $S 100 \beta$ in detecting traumatic intracranial lesions on computed tomography in trauma patients with mild traumatic brain injury and those with extracranial lesions. J. Neurotrauma 2014, 31, 1815-1822. [CrossRef] [PubMed]

14. Hol, E.M.; Pekny, M. Glial fibrillary acidic protein (GFAP) and the astrocyte intermediate filament system in diseases of the central nervous system. Curr. Opin. Cell Biol. 2015, 32, 121-130. [CrossRef] [PubMed]

15. Posti, J.P.; Hossain, I.; Takala, R.S.K.; Liedes, H.; Newcombe, V.; Outtrim, J.; Katila, A.J.; Frantzén, J.; Ala-Seppälä, H.; Coles, J.P.; et al. Glial Fibrillary Acidic Protein and Ubiquitin C-Terminal Hydrolase-L1 Are Not Specific Biomarkers for Mild CT-Negative Traumatic Brain Injury. J. Neurotrauma 2017. [CrossRef] [PubMed]

16. Kou, Z.; Gattu, R.; Kobeissy, F.; Welch, R.D.; O’Neil, B.J.; Woodard, J.L.; Ayaz, S.I.; Kulek, A.; Kas-Shamoun, R.; Mika, V.; et al. Combining biochemical and imaging markers to improve diagnosis and characterization of mild traumatic brain injury in the acute setting: Results from a pilot study. PLoS ONE 2013, 8, e80296. [CrossRef] [PubMed]

17. McMahon, P.J.; Panczykowski, D.M.; Yue, J.K.; Puccio, A.M.; Inoue, T.; Sorani, M.D.; Lingsma, H.F.; Maas, A.I.R.; Valadka, A.B.; Yuh, E.L.; et al. Measurement of the glial fibrillary acidic protein and its breakdown products GFAP-BDP biomarker for the detection of traumatic brain injury compared to computed tomography and magnetic resonance imaging. J. Neurotrauma 2015, 32, 527-533. [CrossRef]

18. Gill, J.; Latour, L.; Diaz-Arrastia, R.; Motamedi, V.; Turtzo, C.; Shahim, P.; Mondello, S.; DeVoto, C.; Veras, E.; Hanlon, D.; et al. Glial fibrillary acidic protein elevations relate to neuroimaging abnormalities after mild TBI. Neurology 2018, 91, e1385-e1389. [CrossRef]

19. Yue, J.K.; Yuh, E.L.; Korley, F.K.; Winkler, E.A.; Sun, X.; Puffer, R.C.; Deng, H.; Choy, W.; Chandra, A.; Taylor, S.R.; et al. Association between plasma GFAP concentrations and MRI abnormalities in patients with CT-negative traumatic brain injury in the TRACK-TBI cohort: A prospective multicentre study. Lancet Neurol. 2019, 18, 953-961. [CrossRef]

20. Mondello, S.; Jeromin, A.; Buki, A.; Bullock, R.; Czeiter, E.; Kovacs, N.; Barzo, P.; Schmid, K.; Tortella, F.; Wang, K.K.; et al. Glial neuronal ratio: A novel index for differentiating injury type in patients with severe traumatic brain injury. J. Neurotrauma 2012, 29, 1096-1104. [CrossRef]

21. Day, I.N.M.; Thompson, R.J. UCHL1 (PGP 9.5): Neuronal biomarker and ubiquitin system protein. Prog. Neurobiol. 2010, 90, 327-362. [CrossRef]

22. Barry, D.M.; Millecamps, S.; Julien, J.-P.; Garcia, M.L. New movements in neurofilament transport, turnover and disease. Exp. Cell Res. 2007, 313, 2110-2120. [CrossRef] [PubMed]

23. Ljungqvist, J.; Zetterberg, H.; Mitsis, M.; Blennow, K.; Skoglund, T. Serum Neurofilament Light Protein as a Marker for Diffuse Axonal Injury: Results from a Case Series Study. J. Neurotrauma 2017, 34, 1124-1127. [CrossRef] [PubMed]

24. Al Nimer, F.; Thelin, E.; Nyström, H.; Dring, A.M.; Svenningsson, A.; Piehl, F.; Nelson, D.W.; Bellander, B.-M. Comparative Assessment of the Prognostic Value of Biomarkers in Traumatic Brain Injury Reveals an Independent Role for Serum Levels of Neurofilament Light. PLoS ONE 2015, 10, e0132177. [CrossRef] [PubMed]

25. Sandsmark, D.K.; Bogoslovsky, T.; Qu, B.-X.; Haber, M.; Cota, M.R.; Davis, C.; Butman, J.A.; Latour, L.L.; Diaz-Arrastia, R. Changes in Plasma von Willebrand Factor and Cellular Fibronectin in MRI-Defined Traumatic Microvascular Injury. Front. Neurol. 2019, 10, 246. [CrossRef] [PubMed]

26. Castellani, R.J.; Perry, G. Tau Biology, Tauopathy, Traumatic Brain Injury, and Diagnostic Challenges. J. Alzheimers Dis. 2019,67,447-467. [CrossRef]

27. Hirad, A.A.; Bazarian, J.J.; Merchant-Borna, K.; Garcea, F.E.; Heilbronner, S.; Paul, D.; Hintz, E.B.; van Wijngaarden, E.; Schifitto, G.; Wright, D.W.; et al. A common neural signature of brain injury in concussion and subconcussion. Sci. Adv. 2019, 5, eaau3460. [CrossRef]

28. Tomita, K.; Nakada, T.-A.; Oshima, T.; Motoshima, T.; Kawaguchi, R.; Oda, S. Tau protein as a diagnostic marker for diffuse axonal injury. PLoS ONE 2019, 14, e0214381. [CrossRef]

29. Ye, L.; Zhang, D.; Shao, M.; Zhao, P.; Yin, B.; Zhuang, J.; Wang, F.; Yan, Z.; Bai, G. Lower Posttraumatic $\alpha$-Synuclein Level Associated With Altered Default Mode Network Connectivity Following Acute Mild Traumatic Brain Injury. Front. Neural Circuits 2019, 13, 26. [CrossRef] 
30. Goforth, P.B.; Ellis, E.F.; Satin, L.S. Enhancement of AMPA-mediated current after traumatic injury in cortical neurons. J. Neurosci. 1999, 19, 7367-7374. [CrossRef]

31. Spaethling, J.M.; Klein, D.M.; Singh, P.; Meaney, D.F. Calcium-permeable AMPA receptors appear in cortical neurons after traumatic mechanical injury and contribute to neuronal fate. J. Neurotrauma 2008, 25, 1207-1216. [CrossRef]

32. Dimou, S.; Lagopoulos, J. Toward objective markers of concussion in sport: A review of white matter and neurometabolic changes in the brain after sports-related concussion. J. Neurotrauma 2014, 31, 413-424. [CrossRef] [PubMed]

33. Dambinova, S.A.; Shikuev, A.V.; Weissman, J.D.; Mullins, J.D. AMPAR peptide values in blood of nonathletes and club sport athletes with concussions. Mil. Med. 2013, 178, 285-290. [CrossRef] [PubMed]

34. Centers for Disease Control and Prevention (CDC). Available online: https://www.cdc.gov/ (accessed on 12 December 2019).

35. Pearson, W.S.; Sugerman, D.E.; McGuire, L.C.; Coronado, V.G. Emergency department visits for traumatic brain injury in older adults in the United States: 2006-08. West. J. Emerg. Med. 2012, 13, 289-293. [CrossRef] [PubMed]

36. Yuh, E.L.; Mukherjee, P.; Lingsma, H.F.; Yue, J.K.; Ferguson, A.R.; Gordon, W.A.; Valadka, A.B.; Schnyer, D.M.; Okonkwo, D.O.; Maas, A.I.R.; et al. Magnetic resonance imaging improves 3-month outcome prediction in mild traumatic brain injury. Ann. Neurol. 2013, 73, 224-235. [CrossRef]

37. Despotović, I.; Goossens, B.; Philips, W. MRI segmentation of the human brain: Challenges, methods, and applications. Comput. Math. Methods Med. 2015, 2015, 450341. [CrossRef]

38. Rheault, F.; De Benedictis, A.; Daducci, A.; Maffei, C.; Tax, C.M.W.; Romascano, D.; Caverzasi, E.; Morency, F.C.; Corrivetti, F.; Pestilli, F.; et al. Tractostorm: The what, why, and how of tractography dissection reproducibility. Hum. Brain Mapp. 2020. [CrossRef]

39. Seabury, S.A.; Gaudette, É.; Goldman, D.P.; Markowitz, A.J.; Brooks, J.; McCrea, M.A.; Okonkwo, D.O.; Manley, G.T.; Adeoye, O.; Badjatia, N.; et al. Assessment of Follow-up Care After Emergency Department Presentation for Mild Traumatic Brain Injury and Concussion: Results From the TRACK-TBI Study. JAMA Netw. Open 2018, 1, e180210. [CrossRef]

40. Trifan, G.; Gattu, R.; Haacke, E.M.; Kou, Z.; Benson, R.R. MR imaging findings in mild traumatic brain injury with persistent neurological impairment. Magn. Reson. Imaging 2017, 37, 243-251. [CrossRef]

41. Stein, M.B.; Jain, S.; Giacino, J.T.; Levin, H.; Dikmen, S.; Nelson, L.D.; Vassar, M.J.; Okonkwo, D.O.; Diaz-Arrastia, R.; Robertson, C.S.; et al. Risk of Posttraumatic Stress Disorder and Major Depression in Civilian Patients After Mild Traumatic Brain Injury: A TRACK-TBI Study. JAMA Psychiatry 2019, 76, 249-258. [CrossRef]

42. Yue, J.K.; Burke, J.F.; Upadhyayula, P.S.; Winkler, E.A.; Deng, H.; Robinson, C.K.; Pirracchio, R.; Suen, C.G.; Sharma, S.; Ferguson, A.R.; et al. Selective Serotonin Reuptake Inhibitors for Treating Neurocognitive and Neuropsychiatric Disorders Following Traumatic Brain Injury: An Evaluation of Current Evidence. Brain Sci. 2017, 7, 93. [CrossRef]

43. Yue, J.K.; Vassar, M.J.; Lingsma, H.F.; Cooper, S.R.; Okonkwo, D.O.; Valadka, A.B.; Gordon, W.A.; Maas, A.I.R.; Mukherjee, P.; Yuh, E.L.; et al. Transforming research and clinical knowledge in traumatic brain injury pilot: Multicenter implementation of the common data elements for traumatic brain injury. J. Neurotrauma 2013, 30, 1831-1844. [CrossRef] [PubMed]

44. Su, Y.S.; Schuster, J.M.; Smith, D.H.; Stein, S.C. Cost-Effectiveness of Biomarker Screening for Traumatic Brain Injury. J. Neurotrauma 2019, 36, 2083-2091. [CrossRef] [PubMed]

45. Calcagnile, O.; Anell, A.; Undén, J. The addition of S100B to guidelines for management of mild head injury is potentially cost saving. BMC Neurol. 2016, 16, 200. [CrossRef] [PubMed]

46. Welch, R.D.; Ayaz, S.I.; Lewis, L.M.; Unden, J.; Chen, J.Y.; Mika, V.H.; Saville, B.; Tyndall, J.A.; Nash, M.; Buki, A.; et al. Ability of Serum Glial Fibrillary Acidic Protein, Ubiquitin C-Terminal Hydrolase-L1, and S100B To Differentiate Normal and Abnormal Head Computed Tomography Findings in Patients with Suspected Mild or Moderate Traumatic Brain Injury. J. Neurotrauma 2016, 33, 203-214. [CrossRef] [PubMed]

47. Papa, L.; Brophy, G.M.; Welch, R.D.; Lewis, L.M.; Braga, C.F.; Tan, C.N.; Ameli, N.J.; Lopez, M.A.; Haeussler, C.A.; Mendez Giordano, D.I.; et al. Time Course and Diagnostic Accuracy of Glial and Neuronal Blood Biomarkers GFAP and UCH-L1 in a Large Cohort of Trauma Patients With and Without Mild Traumatic Brain Injury. JAMA Neurol. 2016, 73, 551-560. [CrossRef] 
48. Bazarian, J.J.; Biberthaler, P.; Welch, R.D.; Lewis, L.M.; Barzo, P.; Bogner-Flatz, V.; Gunnar Brolinson, P.; Büki, A.; Chen, J.Y.; Christenson, R.H.; et al. Serum GFAP and UCH-L1 for prediction of absence of intracranial injuries on head CT (ALERT-TBI): A multicentre observational study. Lancet Neurol. 2018, 17, 782-789. [CrossRef]

49. Evaluation of Automatic Class III Designation For Banyan Brain Trauma Indicator: Decision Memorandum. Available online: https://www.accessdata.fda.gov/cdrh_docs/reviews/DEN170045.pdf (accessed on 19 December 2019).

50. Undén, L.; Calcagnile, O.; Undén, J.; Reinstrup, P.; Bazarian, J. Validation of the Scandinavian guidelines for initial management of minimal, mild and moderate traumatic brain injury in adults. BMC Med. 2015, 13, 292. [CrossRef]

51. Maas, A.I.R.; Menon, D.K.; Adelson, P.D.; Andelic, N.; Bell, M.J.; Belli, A.; Bragge, P.; Brazinova, A.; Büki, A.; Chesnut, R.M.; et al. Traumatic brain injury: Integrated approaches to improve prevention, clinical care, and research. Lancet Neurol. 2017, 16, 987-1048. [CrossRef]

52. Winter, C.; Bell, C.; Whyte, T.; Cardinal, J.; Macfarlane, D.; Rose, S. Blood-brain barrier dysfunction following traumatic brain injury: Correlation of K(trans) (DCE-MRI) and SUVR (99mTc-DTPA SPECT) but not serum S100B. Neurol. Res. 2015, 37, 599-606. [CrossRef]

53. Rubenstein, R.; Chang, B.; Yue, J.K.; Chiu, A.; Winkler, E.A.; Puccio, A.M.; Diaz-Arrastia, R.; Yuh, E.L.; Mukherjee, P.; Valadka, A.B.; et al. Comparing Plasma Phospho Tau, Total Tau, and Phospho Tau-Total Tau Ratio as Acute and Chronic Traumatic Brain Injury Biomarkers. JAMA Neurol. 2017, 74, 1063-1072. [CrossRef]

(C) 2020 by the authors. Licensee MDPI, Basel, Switzerland. This article is an open access article distributed under the terms and conditions of the Creative Commons Attribution (CC BY) license (http://creativecommons.org/licenses/by/4.0/). 